\begin{tabular}{l} 
BENTHAM OPEN \\
CrossMark \\
Content list available at: www.benthamopen.com/TOOPHTJ/ \\
DOI: $10.2174 / 1874364101610010035$ \\
\hline
\end{tabular}

\title{
Intra-Ocular Pressure Measurement in a Patient with a Thin, Thick or Abnormal Cornea
}

\author{
Colin I. Clement ${ }^{1,2,3,4}$, Douglas G.A. Parker ${ }^{1,4}$ and Ivan Goldberg ${ }^{*}, 1,2,3$ \\ ${ }^{1}$ Eye Associates, 4/187 Macquarie Street Sydney NSW 2000, Australia \\ ${ }^{2}$ Glaucoma Unit, Sydney Eye Hospital, Australia \\ ${ }^{3}$ Discipline of Ophthalmology, The University of Sydney, Australia \\ ${ }^{4}$ Gosford and Wyong Eye Surgery, Australia
}

\begin{abstract}
Accurate measurement of intra-ocular pressure is a fundamental component of the ocular examination. The most common method of measuring IOP is by Goldmann applanation tonometry, the accuracy of which is influenced by the thickness and biomechanical properties of the cornea. Algorithms devised to correct for corneal thickness to estimate IOP oversimplify the effects of corneal biomechanics. The viscous and elastic properties of the cornea influence IOP measurements in unpredictable ways, a finding borne out in studies of patients with inherently abnormal and surgically altered corneal biomechanics. Dynamic contour tonometry, rebound tonometry and the ocular response analyzer provide useful alternatives to GAT in patients with abnormal corneas, such as those who have undergone laser vision correction or keratoplasty. This article reviews the various methods of intraocular pressure measurement available to the clinician and the ways in which their utility is influenced by variations in corneal thickness and biomechanics.
\end{abstract}

Keywords: Applanation, corneal pathology, corneal thickness, hysteresis, intraocular pressure.

\section{INTRODUCTION}

Intra-ocular pressure (IOP), the internal pressure of the eye, is determined by the dynamic interaction between rates of aqueous production (F) and drainage (C) as well as episcleral venous pressure (PV) as expressed in the following equation:

$$
\text { IOP }=\text { F/C }+ \text { PV }
$$

The definition of "normal" IOP is based on: (i) the normative distribution of IOP values in population studies, and (ii) the observation that both high and low IOP results in structural/functional damage to the eye. Mean IOP for different populations ranges from 13 to $17 \mathrm{mmHg}[1,2]$. Two standard deviations from the mean, used to define the upper and lower limits within healthy populations, gives an IOP "normal" range of approximately 10-21 mmHg. An IOP above this level is a risk factor for glaucoma onset and progression and is associated with retinal vascular occlusion [3]. Very high IOP, particularly if reached rapidly, can cause symptoms including blurred vision, eye ache, headache, nausea, vomiting, red eye and photophobia. Low IOP, often below $6 \mathrm{mmHg}$, may lead to choroidal effusion, optic nerve swelling, maculopathy and cataract.

Given the potential harm of high or low IOP and that many ocular and systemic conditions (or treatments thereof) alter IOP, IOP measurement is a critical part of the ocular examination. Even though placement of a strain gauge (manometer) within the eye most accurately measures IOP, the risks and time involved make this unacceptable as a clinical routine. Instead clinical IOP assessment is based on an estimate using indirect measurement methods whereby

\footnotetext{
* Address correspondence to this author at the Eye Associates, 4/187 Macquarie Street Sydney NSW 2000. Australia; E-mail: eyegoldberg@gmail.com
} 
the tension at the surface of the eye is recorded and used to extrapolate internal pressure. Such measurements are subjected to the properties of the cornea, including its thickness and biomechanics, both of which may vary between eyes and in different corneal conditions. Sometimes it may be impossible to measure IOP at the corneal surface. Understanding and accounting for these challenges is necessary to estimate IOP accurately without the need for an invasive pressure gauge.

\section{CORNEAL BIOMECHANICS AND IOP}

Possessing a range of biomechanical properties, some of which influence IOP measurements [4], the cornea is composed of hundreds of branching and interlacing collagen lamellae suspended in a proteoglycan matrix with high water content. Interaction of these components imbues the cornea with its rigidity, elasticity and viscoelastic properties. Attempts to quantify these in vivo and derive useful clinical applications have identified corneal hysteresis $(\mathrm{CH})$, an index of the cornea's ability to absorb energy and resist deformation, which influences its capacity to dampen fluctuations in IOP. Surgical procedures or disease states may alter the cornea's intrinsic biomechanical character-istics, including those encompassed by the measurement of $\mathrm{CH}$. Such alterations may influence the accuracy of conventional methods of IOP measurement.

\section{METHODS OF IOP MEASUREMENT}

\section{Goldmann Applanation Tonometry}

First described in the 1950s [5], Goldmann applanation tonometry (GAT) significantly improved previous methods to measure IOP. It soon became the method of choice and remains the gold standard. The GAT estimates IOP by measuring the force required to flatten the central cornea over an area with a diameter of $3.06 \mathrm{~mm}$. Effects of tear film surface tension and corneal thickness are neutralized (when IOP is $20 \mathrm{mmHg}$ and central corneal thickness is $0.52 \mathrm{~mm}$ ) [6] resulting in anterior corneal surface force (the tonometer) equaling posterior corneal surface force (IOP). Accuracy is compromised because this principle makes assumptions, several of which are invalid. The eye is filled with a noncompressible liquid (vitreous), and therefore one would expect applanation to induce a rise in IOP. However, this may be offset by outflow facility whereby applanation may result in increased aqueous outflow and therefore reduced IOP. Anterior and posterior corneal curvatures are not equal and corneal thickness and rigidity may vary widely. Furthermore, GAT is performed manually, which means it is subjected to further sources of error including observer bias. That GAT remains the gold standard for IOP measurement has less to do with accuracy than it does with history, cost, access and ease of use.

\section{Mackay-Marg Tonometry}

Developed at around the same time as GAT, Mackay-Marg tonometry measures the force required to depress a central plunger against the cornea relative to a surrounding flat plate. It is the basis for a number of modern tonometers including the pneumotonometer and the Tono-Pen (Reichert Ophthalmic Instruments) [7]. While its advantages include its portability and lack of influence by the tear film (which is neutralized by the surrounding plate), it works on a principle similar to that for GAT and is subject to many of the same sources of error [8].

\section{Rebound Tonometry}

Commercially available as the iCare tonometer, this device has a $50 \mathrm{~mm}$ stainless steel probe with rounded tip that is horizontally projected by a coaxial two magnet system [9]. On hitting the cornea from a distance of 4-8 mm, the recoiling probe induces a voltage in the solenoid, which is converted to a digital signal. While not affected by the tear film, results from rebound tonometry remain influenced by corneal biomechanics and user error. It has the distinct advantage of being compact, portable, relatively inexpensive and is well tolerated without anesthetic. It is well suited for rapid IOP assessment and for IOP assessment in those intolerant of contact tonometry including children.

\section{Dynamic Contour Tonometry}

Dynamic contour tonometry (DCT) is not influenced by the tear film or the force required to deform the cornea [10]. Automation removes observer bias. A type of Maklakov tonometer, which estimates the area of corneal depression resulting from a constant force, DCT is commercially available as the Pascal Dynamic Contour Tonometer (Zeimer Ophthalmic Instruments AG, Switzerland). It consists of a central pressure transducer surrounded by a large diameter curved footplate contour-matched to the surface of the cornea. The footplate serves to stabilize the surrounding cornea 
while the device measures the average central corneal response to $1 \mathrm{Gm}$ of applied force. Theoretically DCT is more accurate than GAT. However, its usefulness is limited by its cost and lack of portability; it is not suitable for individuals with nystagmus, significant corneal pathology or for those unable to be examined on a slit lamp.

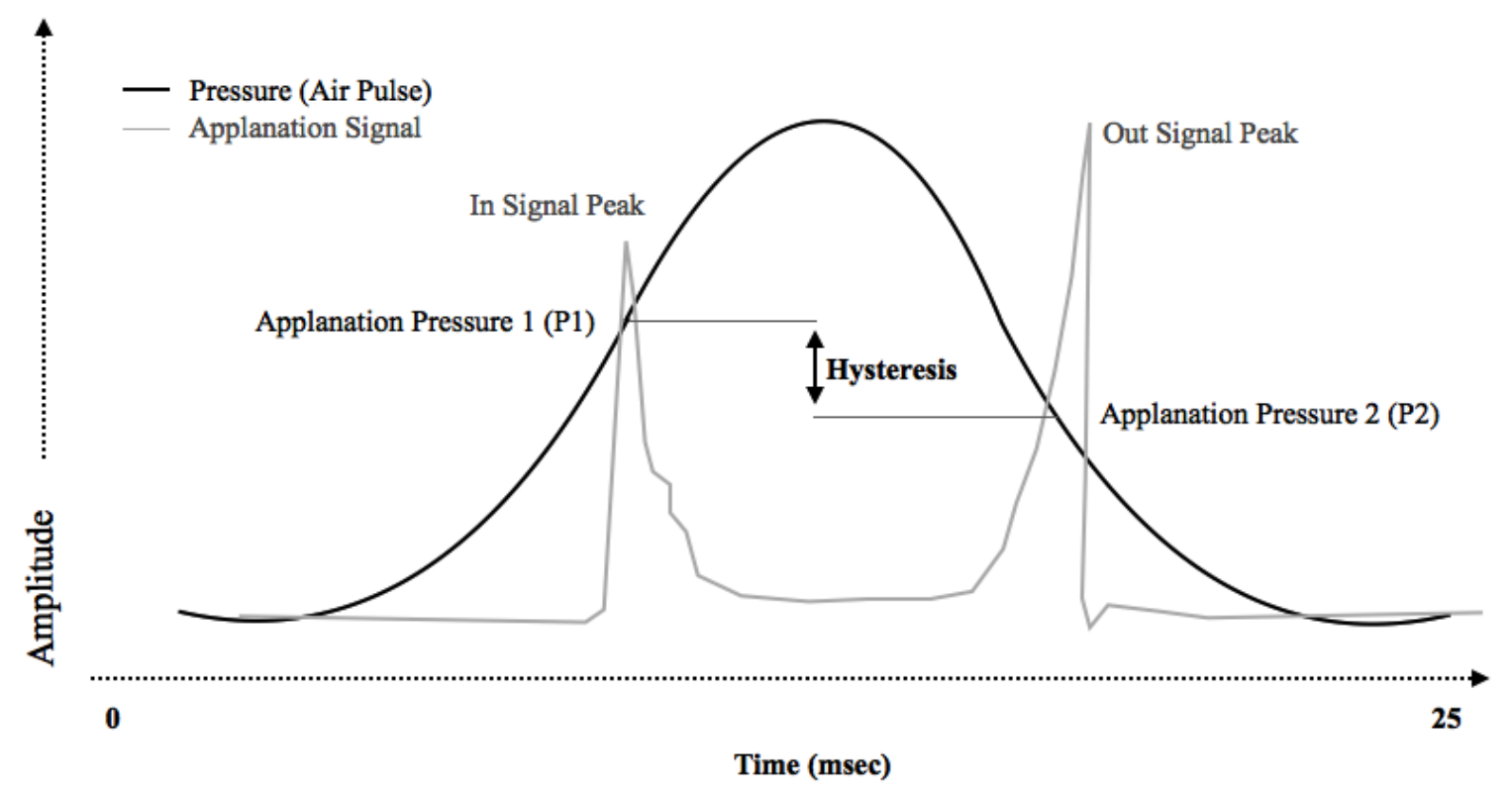

Fig. (1). Representative histogram showing a typical ocular response analyzer (ORA) reading. The applanation signal is a function of air jet pressure during the bi-direction applanation process. Corneal hysteresis is defined as the difference between the pressure required to induced inward corneal applanation (P1) and the pressure at which the cornea bends back outward (P2).

\section{Ocular Response Analyzer}

The Ocular Response Analyzer (ORA) indents the cornea by means of a rapid, collimated pulse of air [11]. The precise timing of corneal flattening during the resultant inward and outward movement is determined by means of an infrared electro-optical system. The pressures (P1 and P2) at each of these events is recorded and used to calculate several parameters. Corneal hysteresis is the difference between the two flattening pressures (P1-P2), and is a reflection of the viscoelastic properties of the cornea (Fig. 1). Corneal resistance factor (CRF) is determined as a linear function of P1 and P2 using a proprietary algorithm, and is thought to reflect the elastic properties of the cornea. A Goldmanncorrelated IOP measurement (IOPg) is determined by calculating the mean of the two pressures P1 and P2, and a cornea-compensated IOP measurement (IOPcc) can also be derived. In addition to these specific measurements, the morphology of the waveform produced by the ORA may also be a useful tool in characterizing alterations in corneal biomechanics in certain conditions or following surgery.

\section{MEASUREMENT OF IOP IN THIN AND THICK CORNEAS}

\section{Defining a Thin or Thick Cornea}

Whether a cornea is considered thin or thick depends on the definition of "normal" or "average" central corneal thickness (CCT). Studies measuring CCT from different populations without corneal pathology provide guidance. Some recent studies are shown in Table 1. Mean CCT for specific populations lie between 510 and 560 microns with the majority closer to 530-550 microns [12 - 31]. Thinnest mean CCT is reported in central/southern Indians, Japanese, West and North Africans, African Americans and Australian Aborigines. Indians residing in Singapore have a considerably thicker mean CCT than Indians living in India. The thickest mean CCT is found in European, White American and Latino populations.

\section{Thick and Thin Corneas in Eyes with Ocular Hypertension and Glaucoma}

The Ocular Hypertension Treatment Study (OHTS) [3] examined the effect of IOP-lowering on conversion rates from ocular hypertension to open-angle glaucoma. Additionally, it provided insights into the way CCT interacts with 
measured IOP, risk of glaucoma onset and response to therapy. Of 1636 eyes, mean CCT was 572.5 microns. This is considerably thicker than mean CCT reported in similar study populations (Table 1). As eyes were entered into the study on the basis of high IOP $(24-32 \mathrm{mmHg})$, the presence of a thicker mean CCT suggests this corneal parameter in part contributed to the measured IOP and thus the inclusion of some individuals. Comparison of eyes that did and did not develop glaucoma showed a significant difference in mean CCT, with the former group having thinner corneas (553.1 microns vs. 574.3 microns). This relationship was highlighted further in multivariate analysis with a hazard ratio for glaucoma onset of 1.71 for every 40 microns thinner CCT. When CCT was measured against response to therapy, an inverse relationship was demonstrated. Eyes with thin CCT displayed greater IOP reductions than did eyes with thick CCT, both at initiation of treatment and through 60 months of follow-up [32]. Explanations for this finding include limitation of ocular drug penetration through thick corneas, a potentially greater effect of corneal rigidity on measured IOP at lower levels, or lower "true" baseline IOP in eyes with thicker CCT (resulting in decreased IOP falls).

Table 1. Recent population based studies of central corneal thickness (CCT).

\begin{tabular}{|c|c|c|c|c|}
\hline Region & Ethnic Group & (n) & Mean CCT & Study \\
\hline \multirow{9}{*}{ Asia } & Singapore Chinese & 3353 & 552 & Chua \\
\hline & Singapore Indian & 3400 & 540 & Chua \\
\hline & Singapore Malay & 3280 & 541 & Chua \\
\hline & Korean & 1259 & 531 & Hwang \\
\hline & Chinese & 1262 & 542 & Wang \\
\hline & Nepalese & 2330 & 539 & Thapa \\
\hline & Southern Indian & 6754 & 511 & Vijaya \\
\hline & Central Indian & 9370 & 514 & Nangia \\
\hline & Japan & 2868 & 521 & Tomidokoro \\
\hline \multirow{4}{*}{ Europe } & Polish & 365 & 563 & Filipecka \\
\hline & German & 4698 & 554 & Hoffman \\
\hline & French & 221 & 553 & Lazreg \\
\hline & Spanish & 357 & 548 & Gros-Otero \\
\hline \multirow{9}{*}{ Africa } & North African & 1662 & 518 & Lazreg \\
\hline & West African & 1011 & $524-531$ & Ntim-Amponsah \\
\hline & Southern Egyptian & 4368 & 530 & Mostafa \\
\hline & African American & 84 & 529 & Haseltine \\
\hline & Latino American & 96 & 545 & Haseltine \\
\hline & White American & 90 & 550 & Haseltine \\
\hline & Latino American & 3685 & 551 & Jiang \\
\hline & Puerto Rican & 588 & 541 & Graeber \\
\hline & American Indian/Alaskan & 429 & 554 & Torres \\
\hline \multirow{3}{*}{ Pacific } & Norfolk Islanders & 781 & 546 & Mackey \\
\hline & Australian Caucasian & 1356 & 540 & Rahman \\
\hline & Australian Aborigine & 1884 & 512 & Landers \\
\hline
\end{tabular}

\section{Correcting for Central Corneal Thickness when Estimating IOP}

With GAT, the countering effects of tear film surface tension and CCT are minimized when the applanation area measures $3.06 \mathrm{~mm}$ in diameter and the CCT is 520 microns (5). When all else is equal, a CCT above this level theoretically will overestimate the true tension and vice versa. Algorithms have been devised to correct for the presumed effect of CCT on IOP readings including those suggested by Ehlers et al. [33], Doughty and Zaman [34] as well as Orssengo and Pye [35]. Use of correction tables has become widespread. However, given that such corrections did not alter the measured effect of mean CCT on IOP changes to treatment in OHTS, the relationship may be more complex. This has been confirmed by subsequent studies that specifically examined this issue. For example, Park et al. [36] compared "corrected" and "uncorrected" GAT to DCT as the reference standard. They found that corrected GAT was no more accurate than uncorrected GAT, with the former showing poorer correlation to DCT measurements, particularly for thicker corneas. Thus CCT correction formulas may reduce, not improve, the accuracy of estimated IOP and points to the potential effects of corneal biomechanical factors unrelated to CCT. Comparison between manometry and CCT-corrected GAT shows this is indeed the case [37]. 


\section{MEASUREMENT OF IOP IN THE ABNORMAL CORNEA}

\section{The Cornea Following Laser Vision Correction}

Due to changes in CCT, IOP measurements may be inaccurate following LASIK or PRK. This is especially significant given many LASIK patients are myopic and spuriously low IOP measurements may result in failure to detect early glaucoma. These ablative procedures not only result in reductions in CCT but also alter the biomechanics of the cornea. This is supported by studies demonstrating that both $\mathrm{CH}$ and CRF decrease following LASIK [38, 39]. Measurements of IOP using both GAT and ORA (to determine IOPg and IOPcc) have shown a significant reduction following LASIK [39]. However, DCT has been reported to be relatively immune to changes in CCT and corneal biomechanics following LASIK [38, 40 - 42]. The DCT may be a preferable method of measuring IOP in patients following LASIK, as unlike GAT it does not rely on a static applanation of the cornea, rendering it less sensitive to alterations in corneal biomechanics.

\section{The Keratoconic or Ectatic Cornea}

High degrees of corneal astigmatism, such as may be found in keratoconus, have been shown to influence GAT measurement of IOP significantly [43]. CH and CRF are lower in corneas with keratoconus compared with normal corneas $[44,45]$. There also appears to be a significant negative correlation between $\mathrm{CH}$ and $\mathrm{CRF}$ and the grade of keratoconus, with greater severity resulting in lower CH and CRF. GAT IOP, IOPg and IOPcc measurements have all been found to underestimate true IOP in keratoconic corneas [39]: there is a tendency to underestimate IOP using applanation methods in corneas with reduced damping capacity. There are limitations in utilizing the ORA to determine $\mathrm{CH}$ and $\mathrm{CRF}$ accurately in corneas with advanced keratoconus or ectasia owing to distortion in the morphology of the waveform signature.

\section{The Edematous Cornea}

In conditions resulting in endothelial decompensation, such as Fuchs' dystrophy, the cornea may swell significantly. Whilst these corneas have an increased CCT, they have reduced CH compared with control eyes [11, 46]; they behave biomechanically similar to keratoconic eyes. There is a tendency to underestimate IOP in such corneas using applanation tonometry.

\section{The Cornea Following Keratoplasty}

$\mathrm{CH}$ decreases following keratoplasty, whilst CRF increases [47]. Penetrating keratoplasty (PK) might be expected to influence corneal biomechanics, it induces significant changes in CCT and corneal astigmatism. The corneal surface may be highly irregular following keratoplasty, especially in the early post-operative period, rendering GAT-determined IOP impossible. Other methods such as pneumatic tonometry, Tono-Pen or iCare tonometry may be useful alternatives. However, the iCare tonometer has been reported to underestimate GAT readings in post-keratoplasty eyes and the two do not appear to be interchangeable for this purpose [48]. Deep anterior lamellar keratoplasty causes similar alterations to corneal biomechanics as PK. For endothelial keratoplasty, such as Descemet's Stripping Automated Endothelial Keratoplasty, patients have an increase in CCT post-operatively, but the IOP is generally not affected [49]. For IOP measurement, GAT remains the gold standard. However, DCT and pneumatic tonometry may also be useful.

\section{The Keratoprosthetic Cornea}

There are two primary forms of keratoprosthesis in use: the oculo-odonto-keratoprosthesis (OOKP) and the Boston Keratoprosthesis (Boston Kpro). In both, the central cornea is replaced with a prosthetic implant, rendering conventional methods of applanation or pneumatic tonometry impossible. Monitoring of IOP in such patients is important, as between 36-76\% of keratoprosthesis patients already have glaucoma, whilst a new diagnosis of glaucoma is made in $2-28 \%$ of Kpro patients post-operatively [50]. Digital tonometry is the most common method to guesstimate IOP in these patients. There are others: a Tono-Pen at the limbus may approximate true IOP and transpalpebral measurements, using devices such as the Diaton. These might be useful.

\section{Other Abnormal States of the Cornea}

A high degree of regular astigmatism in a cornea may render inaccurate measurement of IOP with applanation tonometry. One can minimize this by measuring the IOP twice, firstly with the tonometer head aligned along the steep axis, and secondly along the flat axis. The mean of the two measurements is then recorded as the IOP. Irregular 
astigmatism may develop in a cornea subjected to chemical or mechanical injury, distorting the mires during GAT measurements. Salzmann's nodular degeneration may make applanation tonometry unreliable. Under these circumstances GAT may provide only an estimate of true IOP. Rebound tonometry instruments such as the iCare tonometer, which do not require applanation, may be useful options with irregular astigmatism.

In collagen cross-linking, riboflavin drops are applied to the cornea followed by ultraviolet irradiation; this induces biochemical changes in collagen fibrils, stiffening the keratoconic cornea [51]. Such stiffening alters the biomechanics of the cornea and may alter the measurement of IOP. Perhaps reassuringly, Vinciguerra [52] reported an increase in $\mathrm{CH}$ and CRF during the impregnation and irradiation phases of cross-linking, but did not find an induced effect on IOP.

Diabetes mellitus is commonly associated with thicker corneas and an increase in IOP [53]. Scheler found no difference in $\mathrm{CH}$ or CRF between controls and well-controlled diabetics [53]. However, $\mathrm{CH}$ tended to be higher and CRF was significantly higher, in poorly-controlled diabetics compared with controls. This may be from an increase in the viscosity of the ground substance of the cornea in patients with elevated $\mathrm{HbAlc}$, leading to higher corneal resistance and a falsely high IOP measurement.

\section{SUMMARY}

Accurate measurement of IOP is a fundamental component of the ocular examination. It facilitates the diagnosis and management of patients with established glaucoma and the identification of patients with an elevated risk of developing glaucoma. For over 50 years, the most common method of measuring IOP has been by GAT, largely on account of its low cost and ease of use. However, as we understand corneal biomechanics better, we increasingly appreciate GAT's limitations. We overestimate IOP in thick corneas and underestimate it in thin corneas. Algorithms to correct for CCT to estimate IOP oversimplifies the effects of corneal biomechanics. Corneal thickness is but one component of a complex interaction between the viscous and elastic properties of the cornea, which ultimately combine to influence IOP measurements in not entirely predictable ways. This has been born out in studies of patients with inherently abnormal and surgically altered corneal biomechanics. Newer methods of IOP estimation, including DCT and the ORA, provide valuable alternatives to GAT in patients with abnormal corneas. While there is no single method which provides an easy, quick and accurate result in all cases, the practitioner must rely on well-established methods informed by an understanding of their limitations. With ongoing research, new techniques promise to increase our understanding of the complex interplay between the cornea and the measurement of IOP.

\section{CONFLICT OF INTEREST}

The authors confirm that this article content has no conflict of interest.

\section{ACKNOWLEDGEMENTS}

Declared none.

\section{REFERENCES}

[1] Shiose Y, Kitazawa Y, Tsukahara S, et al. Epidemiology of glaucoma in Japan-a nationwide glaucoma survey. Jpn J Ophthalmol 1991; 35(2): 133-55. [PMID: 1779484]

[2] Kahn HA, Leibowitz HM, Ganley JP, et al. The Framingham Eye Study. I. Outline and major prevalence findings. Am J Epidemiol 1977; 106(1): 17-32. [PMID: 879158]

[3] Gordon MO, Beiser JA, Brandt JD, et al. The Ocular Hypertension Treatment Study: baseline factors that predict the onset of primary openangle glaucoma. Arch Ophthalmol 2002; 120(6): 714-20. [http://dx.doi.org/10.1001/archopht.120.6.714] [PMID: 12049575]

[4] Congdon NG, Broman AT, Bandeen-Roche K, Grover D, Quigley HA. Central corneal thickness and corneal hysteresis associated with glaucoma damage. Am J Ophthalmol 2006; 141(5): 868-75. [http://dx.doi.org/10.1016/j.ajo.2005.12.007] [PMID: 16527231]

[5] Goldmann H, Schmidt T. Uber Applanationstonometrie. Ophthalmologica 1957; 134(4): 221-42. [http://dx.doi.org/10.1159/000303213] [PMID: 13484216]

[6] Ehlers N, Hansen FK. Central corneal thickness in low-tension glaucoma. Acta Ophthalmol (Copenh) 1974; 52(5): 740-6. [http://dx.doi.org/10.1111/j.1755-3768.1974.tb01109.x] [PMID: 4479566]

[7] Kao SF, Lichter PR, Bergstrom TJ, Rowe S, Musch DC. Clinical comparison of the Oculab Tono-Pen to the Goldmann applanation 
tonometer. Ophthalmology 1987; 94(12): 1541-4.

[http://dx.doi.org/10.1016/S0161-6420(87)33249-X] [PMID: 3431824]

[8] Bhan A, Browning AC, Shah S, Hamilton R, Dave D, Dua HS. Effect of corneal thickness on intraocular pressure measurements with the pneumotonometer, Goldmann applanation tonometer, and Tono-Pen. Invest Ophthalmol Vis Sci 2002; 43(5): 1389-92. [PMID: 11980851]

[9] Iliev ME, Goldblum D, Katsoulis K, Amstutz C, Frueh B. Comparison of rebound tonometry with Goldmann applanation tonometry and correlation with central corneal thickness. Br J Ophthalmol 2006; 90(7): 833-5. [http://dx.doi.org/10.1136/bjo.2005.089870] [PMID: 16672330]

[10] Kanngiesser HE, Kniestedt C, Robert YC. Dynamic contour tonometry: presentation of a new tonometer. J Glaucoma 2005; 14(5): 344-50. [http://dx.doi.org/10.1097/01.ijg.0000176936.16015.4e] [PMID: 16148581]

[11] Luce DA. Determining in vivo biomechanical properties of the cornea with an ocular response analyzer. J Cataract Refract Surg 2005; 31(1): $156-62$

[http://dx.doi.org/10.1016/j.jcrs.2004.10.044] [PMID: 15721708]

[12] Chua J, Tham YC, Liao J, et al. Ethnic differences of intraocular pressure and central corneal thickness: the Singapore Epidemiology of Eye Diseases study. Ophthalmology 2014; 121(10): 2013-22. [http://dx.doi.org/10.1016/j.ophtha.2014.04.041] [PMID: 24950592]

[13] Mostafa EM. Central corneal thickness in southern Egypt. Int Ophthalmol 2014; 34(4): 809-15. [http://dx.doi.org/10.1007/s10792-013-9885-5] [PMID: 24272277]

[14] Filipecka I, Nowak A, Lewicka K, Kapustka B, Damek J, Owczarek A. Evaluate central corneal thickness in patients from Podbeskidzie area in adult patients. Klin Oczna 2013; 115(2): 121-4. [PMID: 24059027]

[15] Hoffmann EM, Lamparter J, Mirshahi A, et al. Distribution of central corneal thickness and its association with ocular parameters in a large central European cohort: the Gutenberg health study. PLoS One 2013; 8(8): e66158. [http://dx.doi.org/10.1371/journal.pone.0066158] [PMID: 23936291]

[16] Lazreg S, Mesplié N, Praud D, et al. Comparison of corneal thickness and biomechanical properties between North African and French patients. J Cataract Refract Surg 2013; 39(3): 425-30. [http://dx.doi.org/10.1016/j.jcrs.2012.09.015] [PMID: 23332117]

[17] Hwang YH, Kim HK, Sohn YH. Central corneal thickness in a Korean population: the Namil Study 2012. [http://dx.doi.org/10.1167/iovs.12-10173]

[18] Haseltine SJ, Pae J, Ehrlich JR, Shammas M, Radcliffe NM. Variation in corneal hysteresis and central corneal thickness among black, hispanic and white subjects. Acta Ophthalmol 2012; 90(8): e626-31. [http://dx.doi.org/10.1111/j.1755-3768.2012.02509.x] [PMID: 22938724]

[19] Ntim-Amponsah CT, Seidu AY, Essuman VA, et al. A study of central corneal thickness in glaucoma and nonglaucoma patients in a West African population. Cornea 2012; 31(10): 1093-6. [http://dx.doi.org/10.1097/ICO.0b013e31823c51f7] [PMID: 22902491]

[20] Jiang X, Varma R, Wu S, et al. Baseline risk factors that predict the development of open-angle glaucoma in a population: the Los Angeles Latino Eye Study. Ophthalmology 2012; 119(11): 2245-53.

[http://dx.doi.org/10.1016/j.ophtha.2012.05.030] [PMID: 22796305]

[21] Wang D, Huang W, Li Y, et al. Intraocular pressure, central corneal thickness, and glaucoma in chinese adults: the liwan eye study. Am J Ophthalmol 2011; 152(3): 454-62.el. [http://dx.doi.org/10.1016/j.ajo.2011.03.005] [PMID: 21679915]

[22] Gros-Otero J, Arruabarrena-Sánchez C, Teus M. Central corneal thickness in a healthy Spanish population. Arch Soc Esp Oftalmol 2011; 86(3): 73-6.

[http://dx.doi.org/10.1016/j.oftal.2010.12.008] [PMID: 21511100]

[23] Thapa SS, Paudyal I, Khanal S, Paudel N, Mansberger SL, van Rens GH. Central corneal thickness and intraocular pressure in a Nepalese population: the Bhaktapur Glaucoma Study. J Glaucoma 2012; 21(7): 481-5. [http://dx.doi.org/10.1097/IJG.0b013e3182182c0f] [PMID: 21499121]

[24] Mackey DA, Sherwin JC, Kearns LS, et al. The Norfolk Island Eye Study (NIES): rationale, methodology and distribution of ocular biometry (biometry of the bounty). Twin Res Hum Genet 2011; 14(1): 42-52. [http://dx.doi.org/10.1375/twin.14.1.42] [PMID: 21314255]

[25] Vijaya L, George R, Arvind H, et al. Central corneal thickness in adult South Indians: the Chennai Glaucoma Study. Ophthalmology 2010; 117(4): 700-4.

[http://dx.doi.org/10.1016/j.ophtha.2009.09.025] [PMID: 20079536]

[26] Nangia V, Jonas JB, Sinha A, Matin A, Kulkarni M. Central corneal thickness and its association with ocular and general parameters in Indians: the Central India Eye and Medical Study. Ophthalmology 2010; 117(4): 705-10. [http://dx.doi.org/10.1016/j.ophtha.2009.09.003] [PMID: 20045561]

[27] Graeber CP, Torres MB, Shields MB. Central corneal thickness in a Puerto Rican population. J Glaucoma 2008; 17(5): 356-60. 
[http://dx.doi.org/10.1097/IJG.0b013e31815c5f15] [PMID: 18703944]

[28] Torres RJ, Jones E, Edmunds B, Becker T, Cioffi GA, Mansberger SL. Central corneal thickness in Northwestern American Indians/Alaskan Natives and comparison with White and African-American persons. Am J Ophthalmol 2008; 146(5): 747-51. [http://dx.doi.org/10.1016/j.ajo.2008.05.047] [PMID: 18672219]

[29] Tomidokoro A, Araie M, Iwase A. Corneal thickness and relating factors in a population-based study in Japan: the Tajimi study. Am J Ophthalmol 2007; 144(1): 152-4. [http://dx.doi.org/10.1016/j.ajo.2007.02.031] [PMID: 17601447]

[30] Rahman ML, Bunce C, Healey PR, et al. Commingling analyses of central corneal thickness and adjusted intraocular pressure in an older Australian population. Invest Ophthalmol Vis Sci 2010; 51(5): 2512-8. [http://dx.doi.org/10.1167/iovs.09-4270] [PMID: 20071671]

[31] Landers J, Henderson T, Craig J. Distribution and associations of intraocular pressure in indigenous Australians within central Australia: the Central Australian Ocular Health Study. Clin Experiment Ophthalmol 2011; 39(7): 607-13. [http://dx.doi.org/10.1111/j.1442-9071.2011.02507.x] [PMID: 22452681]

[32] Brandt JD, Beiser JA, Gordon MO. Kass MA and the ocular hypertension treatment study (OHTS) group. Central corneal thickness and measured IOP response to ocular hypotensive medication in the ocular hypertension treatment study. Am J Ophthalmol 2004; 138: 717-22. [http://dx.doi.org/10.1016/j.ajo.2004.07.036] [PMID: 15531304]

[33] Ehlers N, Hansen FK, Aasved H. Biometric correlations of corneal thickness. Acta Ophthalmol (Copenh) 1975; 53(4): 652-9. [http://dx.doi.org/10.1111/j.1755-3768.1975.tb01784.x] [PMID: 1242286]

[34] Doughty MJ, Zaman ML. Human corneal thickness and its impact on intraocular pressure measures: a review and meta-analysis approach. Surv Ophthalmol 2000; 44(5): 367-408. [http://dx.doi.org/10.1016/S0039-6257(00)00110-7] [PMID: 10734239]

[35] Orssengo GJ, Pye DC. Determination of the true intraocular pressure and modulus of elasticity of the human cornea in vivo. Bull Math Biol 1999; 61(3): 551-72. [http://dx.doi.org/10.1006/bulm.1999.0102] [PMID: 17883231]

[36] Park SJ, Ang GS, Nicholas S, Wells AP. The effect of thin, thick, and normal corneas on Goldmann intraocular pressure measurements and correction formulae in individual eyes. Ophthalmology 2012; 119(3): 443-9. [http://dx.doi.org/10.1016/j.ophtha.2011.07.058] [PMID: 22035576]

[37] Feltgen N, Leifert D, Funk J. Correlation between central corneal thickness, applanation tonometry, and direct intracameral IOP readings. Br J Ophthalmol 2001; 85(1): 85-7. [http://dx.doi.org/10.1136/bjo.85.1.85] [PMID: 11133718]

[38] Pepose JS, Feigenbaum SK, Qazi MA, Sanderson JP, Roberts CJ. Changes in corneal biomechanics and intraocular pressure following LASIK using static, dynamic, and noncontact tonometry. Am J Ophthalmol 2007; 143(1): 39-47. [http://dx.doi.org/10.1016/j.ajo.2006.09.036] [PMID: 17188041]

[39] Touboul D, Roberts C, Kérautret J, et al. Correlations between corneal hysteresis, intraocular pressure, and corneal central pachymetry. J Cataract Refract Surg 2008; 34(4): 616-22. [http://dx.doi.org/10.1016/j.jcrs.2007.11.051] [PMID: 18361984]

[40] Kaufmann C, Bachmann LM, Thiel MA. Intraocular pressure measurements using dynamic contour tonometry after laser in situ keratomileusis. Invest Ophthalmol Vis Sci 2003; 44(9): 3790-4. [http://dx.doi.org/10.1167/iovs.02-0946] [PMID: 12939293]

[41] Siganos DS, Papastergiou GI, Moedas C. Assessment of the Pascal dynamic contour tonometer in monitoring intraocular pressure in unoperated eyes and eyes after LASIK. J Cataract Refract Surg 2004; 30(4): 746-51. [http://dx.doi.org/10.1016/j.jcrs.2003.12.033] [PMID: 15093634]

[42] Duba I, Wirthlin AC. Dynamic contour tonometry for post-LASIK intraocular pressure measurements. Klin Monatsbl Augenheilkd 2004; 221(5): $347-50$ [http://dx.doi.org/10.1055/s-2004-812895] [PMID: 15162277]

[43] Rask G, Behndig A. Effects of corneal thickness, curvature, astigmatism and direction of gaze on Goldmann applanation tonometry readings. Ophthalmic Res 2006; 38(1): 49-55. [http://dx.doi.org/10.1159/000089762] [PMID: 16293977]

[44] Shah S, Laiquzzaman M, Bhojwani R, Mantry S, Cunliffe I. Assessment of the biomechanical properties of the cornea with the ocular response analyzer in normal and keratoconic eyes. Invest Ophthalmol Vis Sci 2007; 48(7): 3026-31. [http://dx.doi.org/10.1167/iovs.04-0694] [PMID: 17591868]

[45] Ortiz D, Piñero D, Shabayek MH, Arnalich-Montiel F, Alió JL. Corneal biomechanical properties in normal, post-laser in situ keratomileusis, and keratoconic eyes. J Cataract Refract Surg 2007; 33(8): 1371-5. [http://dx.doi.org/10.1016/j.jcrs.2007.04.021] [PMID: 17662426]

[46] del Buey MA, Cristóbal JA, Ascaso FJ, Lavilla L, Lanchares E. Biomechanical properties of the cornea in Fuchs' corneal dystrophy. Invest Ophthalmol Vis Sci 2009; 50(7): 3199-202. [http://dx.doi.org/10.1167/iovs.08-3312] [PMID: 19255149] 
[47] Shin JY, Choi JS, Oh JY, Kim MK, Lee JH, Wee WR. Evaluation of corneal biomechanical properties following penetrating keratoplasty using the ocular response analyzer. Korean J Ophthalmol 2010; 24(3): 139-42. [http://dx.doi.org/10.3341/kjo.2010.24.3.139] [PMID: 20532138]

[48] Salvetat ML, Zeppieri M, Miani F, Tosoni C, Parisi L, Brusini P. Comparison of iCare tonometer and Goldmann applanation tonometry in normal corneas and in eyes with automated lamellar and penetrating keratoplasty. Eye (Lond) 2011; 25(5): 642-50. [http://dx.doi.org/10.1038/eye.2011.60] [PMID: 21436848]

[49] Vajaranant TS, Price MO, Price FW, Wilensky JT, Edward DP. Intraocular pressure measurements following Descemet stripping endothelial keratoplasty. Am J Ophthalmol 2008; 145(5): 780-6.

[http://dx.doi.org/10.1016/j.ajo.2008.01.010] [PMID: 18329627]

[50] Banitt M. Evaluation and management of glaucoma after keratoprosthesis. Curr Opin Ophthalmol 2011; 22(2): 133-6. [http://dx.doi.org/10.1097/ICU.0b013e328343723d] [PMID: 21191292]

[51] Wollensak G, Spoerl E, Seiler T. Stress-strain measurements of human and porcine corneas after riboflavin-ultraviolet-A-induced crosslinking. J Cataract Refract Surg 2003; 29(9): 1780-5. [http://dx.doi.org/10.1016/S0886-3350(03)00407-3] [PMID: 14522301]

[52] Vinciguerra P, Albè E, Mahmoud AM, Trazza S, Hafezi F, Roberts CJ. Intra and postoperative variation in ocular response analyzer parameters in keratoconic eyes after corneal cross-linking. J Refract Surg 2010; 26(9): 669-76. [http://dx.doi.org/10.3928/1081597X-20100331-01] [PMID: 20438025]

[53] Scheler A, Spoerl E, Boehm AG. Effect of diabetes mellitus on corneal biomechanics and measurement of intraocular pressure. Acta Ophthalmol 2012; 90(6): e447-51.

[http://dx.doi.org/10.1111/j.1755-3768.2012.02437.x] [PMID: 22691299]

Received: July 26, 2015

Revised: August 18, 2015

Accepted: August 18, 2015

(C) Clement et al.; Licensee Bentham Open.

This is an open access article licensed under the terms of the Creative Commons Attribution-Non-Commercial 4.0 International Public License (CC BY-NC 4.0) (https://creativecommons.org/licenses/by-nc/4.0/legalcode), which permits unrestricted, non-commercial use, distribution and reproduction in any medium, provided the work is properly cited. 